\title{
COPD and Intestinal Dysbiosis
}

\author{
R.S. Bayramova*, M.S. Novruzova, H.M. Aliyeva and J.X. Talibova \\ Azerbaijan Medical University, Department of Medical Microbiology and Immunology, \\ Azerbaijan \\ *Corresponding author
}

\section{A B S T R A C T}

\begin{tabular}{|l|}
\hline K e y w o r d s \\
$\begin{array}{l}\text { Chronic obstructive } \\
\text { pulmonary, Secondary } \\
\text { immunodeficiency, } \\
\text { Inflammatory process, } \\
\text { Chronization, Phagitosis } \\
\text { activity, Normal intestinal } \\
\text { microflora, Dysbiotic } \\
\text { changes, Bifidus bacteria } \\
\text { and lactobacilli, E.coli }\end{array}$ \\
\hline Article Info \\
\hline $\begin{array}{l}\text { Accepted: } \\
\text { 20 June } 2019 \\
\text { Available Online: } \\
\text { 10 July 2019 }\end{array}$ \\
\hline
\end{tabular}

\section{Keywords}

Chronic obstructive pulmonary, Secondary activity, Normal intestinal microflora, Dysbiotic and lactobacilli, E.coli

\section{Introduction}

Today, chronic obstructive pulmonary disease (COPD) is the most common disease of the bronchopulmonary system, leading to a decrease in the quality of life of patients and is characterized by frequent infectious-related exacerbations. Every new exacerbation not only increases the risk of reducing respiratory function, but also causes a higher incidence of antibiotic therapy $(1,2)$

By WHO forecasts, a further increase in the prevalence and mortality of COPD among people of working age is predicted, due to uncontrolled environmental pollution, a tobacco pandemic, an increase in the level of allergens and a genetic predisposition $(3,4,5$, 6). In terms of environmental and social disadvantage in patients with COPD, the immune system is inhibited, leading to the formation of secondary immunodeficiency and transformation of acute respiratory system diseases into a protracted chronic form (7.8)

When chronization and progression of COPD, there is a violation of cellular and humoral immunity, production of pro-inflammatory 
cytokines of phagocytic cell activity that contribute to the persistence of the inflammatory process in the lungs $(9,10,11$, $12,13)$

It has been established that bronchial tree infections are the leading cause of COPD exacerbation. Bacterial pathogens in significant quantities are detected in 50-70\% of patients with exacerbation of the disease. The role of gram-negative microflora (Hemophilus influenza, Moraxella catarralis) increases in people with severe COPD $(14,15$, $16,17)$. In the period of infectious exacerbation of COPD, the intensification of the inflammatory process, leading to deterioration in the ventilation function of the lungs, lengthens the recovery process. As COPD progresses, exacerbations become frequent (18).

Conducted etiotropic therapy aimed at eliminating the infectious process increases the incidence of adverse reactions from the gastrointestinal tract (diarrhea, colitis, excessive bacterial growth syndrome), the widespread use of antibacterial drugs reduces the duration of exacerbations, but causes intestinal dysbiosis and antibiotic resistance.

It is proved that the normal intestinal microflora of a healthy person protects against colonization by pathogenic microorganisms and participates in the implementation of immunological defense mechanisms. When the species and quantitative composition of the intestinal microflora, developing as a result of the underlying disease or on the background of antibacterial therapy, change not only the digestive processes, but also the immune mechanisms that lead to local and systemic disorders in the internal environment of the microorganism through the release of proinflammatory and anti-inflammatory cytokines, regulatory peptides regeneration and apoptosisn $(8,19,20,21)$.
Therefore, the study of the state of intestinal microflora in patients with COPD and the timely correction of impaired microbiocinosis is an important task that needs to be studied.

\section{Materials and Methods}

Surveyed 20 people, of whom $11(\mathrm{n}=11)$ patients with moderate COPD who were treated in the pulmonary department, 9 people - almost healthy individuals made up the control group $(n=9)$. The average age of the subjects was $56 \pm 5.4$ years. The observed patients received antibiotic therapy in the last year. The diagnosis of COPD was made by clinicians on the basis of clinical and instrumental methods of examination. All patients underwent feces for dysbacteriosis, taking into account the number of Bifidobacteria, Lactobacilli, E.coli with normal enzymatic activity and hemolyzing Escherichia coli, as well as other conditional pathogenic microorganisms (UPM).

In patients with COPD, the intensity of inflammation of the bronchial mucosa was assessed. Phagocytic activity of neutrophils (PAN), phagocytic number (PN), and the intensity of neutrophil oxygen-dependent metabolism in the spontaneous and induced nitro-tetrazolium recovery (NBT) test were determined.

The results were processed using the Statistic 6.0 program. The significance of differences in the comparative parameters was determined by the criterion of the Student. To determine the relationship between the individual indicators used the correlation analysis according to Pearson.

\section{Results and Discussion}

On the basis of anamnestic data, in most patients with COPD, in addition to respiratory symptoms, there were complaints from the 
gastrointestinal tract: nausea, belching, and stool dysfunction or diarrhea. Dysbiotic changing was assessed by N. M. Grachova's classification (22).

I degree of dysbacteriosis was characterized by a decrease in the total number of the main representatives of microflora (bifido bacteria and lactobacilli to $10^{7} \mathrm{CFU} / \mathrm{g}$ ), a decrease in the number of intestinal basils with normal fermentation activity to $10^{6} \mathrm{CFU} / \mathrm{g}$.

The II degree of intestinal dysbacteriosis was manifested by a decrease in the level of microflora (bifidus bacteria and lactobacilli to $105 \mathrm{CFU} / \mathrm{g}$ ), an increase in lactose-negative E. coli and an increase in the level of conditionally pathogenic enterobacteria.
The III degree of dysbacteriosis is expressed by a strong decrease in the total amount of intestinal microflora (Bifidobacteria and Lactobacilli to $103 \mathrm{CFU} / \mathrm{g}$ ), the absence of Escherichia with normal enzymatic activity, an increase in the level of conditionally pathogenic enterobacteria, Staphylococcus aureus, of the Candida genus $105 \mathrm{CFU} / \mathrm{g}$.

The studied indicators of the state of the immune status in patients with COPD investigated the functional activity of neutrophils in patients with COPD: phagocytic number (PP), phagocytic index (PI) and NBT.

The study of neutrophil phagocytic index in the control group $(\mathrm{n}=9)$ showed that the PI was $67.1 \pm 2.37 \%$, the PP $-2.1 \pm 0.08$ cells.

\begin{tabular}{|l|l|l|}
\hline The degree of intestinal dysbiosis & Control group $(\mathbf{n = 9})$ & Group of patients with COPD $(\mathbf{n = 1 1})$ \\
\hline I degree & - & $2(18,1 \%)$ \\
\hline II degree & - & $5(45,4 \%)$ \\
\hline III degree & - & $4(36,3 \%)$ \\
\hline IV degree & - & - \\
\hline
\end{tabular}

In the study of the function of phagocytosis in the group of patients with COPD $(n=11)$, there was a clear tendency to decrease in PI $52.1 \pm 1.15 \%$. Apparently, in patients with COPD, opsonizes are depleted, in particular, the $\mathrm{C} 3$ component of complement and IgG (23).

In the study of PP in patients with COPD, the values were higher than the control group (2.1 \pm 0.08 ) and amounted to $2.5 \pm 0.11$, which could be associated with the most pronounced activation of neutrophils in these patients.

The study of NBT-test (neutrophil phagocytic activity) showed that in patients with COPD there was an increase in both spontaneous and induced NBT-test compared with the control group. If in the group of healthy individuals $(\mathrm{n}=9)$ the mean values of the spontaneous NBT test were $9.2 \pm 2.31$ units, the induced
NBT test was $14.5 \pm 2.14$ units, then among patients with COPD the values were $15.1 \pm$ $1.08 \mathrm{U}$ and $19.2 \pm 3.14 \mathrm{U}$ accordingly.

Thus, patients with COPD have a chronic inflammatory process in the bronchopulmonary system, accompanied by inhibition of the functional activity of neutrophils, which complicates the formation of humoral immunity and leads to a persistent course of the disease with frequent exacerbations.

The revealed violations of COPD associated with intestinal dysbacteriosis indicate pronounced manifestations of secondary immunodeficiency.

The obtained data allow us to recommend bacteriological and immunological examination of patients with COPD to 
identify immunological deficiencies with concomitant intestinal dysbiosis for the purpose of complex treatment with the use of immunocorrecting and probiotics.

\section{References}

1. Global Initiative for Chronic Obstructive Lung Disease URL. GOLD Repost 2011 Feb. 21;

2. Avdeev SN. Antibacterial therapy for exacerbation of COPD. Pulmonology. 2010. №2 from 96-107

3. Global Initiative for Chronic Obstructive Pulmonary Disease NHLBI / WHO. Workshop repost. Updated 2010;

4. Chuchalin AG Tobacco Smoking and Soreness of the Organs, Breathing. Russian. Med. Journal 2008 No. 22. C1477-1481;

5. Abdullayev A.Yu. Pulmonary Hypertension in COPD. Biomedicine, 2010, No. 4, pp. 7-11;

6. Fromer L., Cooper CB. Review of the guidelines and the COPD. Int. J. Clin. Pract., 2008 vol. 62, No. 8, p. 12191236.

7. Kirillov SM, Kirillov MM. Pathology of the digestive system in patients with bronchial asthma and COPD: comparative analysis. Pulmonology. 2010. No. 5, pp. 85-89;

8. L/Knott, J. Cox. Immunodeficiency primary and secondary. 23. Oct 2015. P 156-167

9. Grigoriev R. Nicotine and neutrophils. Knowledge and Strength, 2012, №6, p. 95-98.

10. Poplavskaya EE, Lis MA The state of endothelium function and phagitosis activity in COPD and coronary heart disease. Journal of Grodno State Medical University, 2010, №1 (29), pp. 29-31.
11. Gadek JE, Fells GA, Crystal RG Cigarette smoking induces functional antiproteasi deficiency in the lower respiratory tract of humans. Scence, 2010, No. 3, p. 152-156

12. Barnes PJ, The cytokine network in chronic obstructive pulmonary disease. Am. J. Pespir. Cell. Mol.Biofq. 2009; Vol.41, No. 6. P.631-638.

13. Guseinov H.Yu. COPD Treatment Programs. Azerb. Med. Magazine, 2005, No. 1, p. 181-183.)

14. Kolosova K.Y. Exacerbations and progression of COPD. Ural Medical Journal, 2007, №8 (36) p. 21-29).

15. Chin H., Manzel. J., Lehman E.E. et al. Haemophilus influenzae from patients with chronic obstructive pulmonary disease exacerbation induce more inflammation than colonizers. Am. J. Respir. Crit. Care Med., 2005, № 172, p. 85-91.

16. Fedosenko S.V., Oqorodova L.M., Freydin M.B. Microorganisms association ingredients in lower respiratory system of COPD.II Clin medicine/ 2014, N8, p26-32

17. Weinreich U.M., Korsgaard J Bakterial colonization of lower airways in health and chronic lung disease. Clin Respir J., 2008, № 2, p. 116-122.

18. Wang D., Cui X. Evaluation of PDE 4 inhibition for COPD. Jnt. Chron. Obstruct. Pulmon. Dis. 2006 No. 1 (4) p. 373-379

19. Farkhutdinov UR., Farkhutdinov Sh.U. Efficiency of immunocorrective therapy in patients with chronic obstructive pulmonary disease. Pulmonology. 2008. No. 5. P. 60-74.

20. E.P. Yakovenko (et al.,) Syndrome of excessive bacterial growth in the intestine - clinical significance and therapy issues /. Consilium medicum. Extra-issue. 2006. C.3-8. 
21. EP Yakovenko (et al.,) Disruption of the normal composition of intestinal bacteria: clinical significance and treatment issues. Rus. honey. Journals 2008. V. 10, No. 2. P.41-46.

22. Sulima M.V., Soluyanova I.P., Kruglyakova L.V., Disturbance of intestinal microflora normal composition in digestive system diseases. Blagoveshensk; 2014, p. 104

23. Daldegan M.B., Teixera M.M., Talvani A. Concentration of CCL 11, CXCL8 and TNF ain sputum and plasma of patients undergoing asthma or chronic obstructive pulmonary disease exacerbation. Braz J.Med. Biol.Res., 2005, Vol.38, №9, p. 85-91.

\section{How to cite this article:}

Bayramova, R.S., M.S. Novruzova, H.M. Aliyeva and Talibova, J.X. 2019. COPD and Intestinal Dysbiosis. Int.J.Curr.Microbiol.App.Sci. 8(07): 2656-2660.

doi: https:. doi.org/10.20546/ijcmas.2019.807.327 